\title{
Los nombres de lugar como elementos evocadores del paisaje histórico. Análisis de la toponimia de los núcleos de población de la cuenca del Vinalopó ${ }^{1}$
}

\author{
Place names as evocative elements of historical landscape. \\ Analysis of urban place names in the Vinalopó Basin
}

\author{
Joan Carles Membrado-Tena ${ }^{2}$ (i) \\ Emilio Iranzo-García ${ }^{3}$ (iD
}

\section{Resumen}

La cuenca del Vinalopó, al sur del País Valenciano, está compuesta por una serie de comarcas industriales densamente pobladas que han sido habitadas desde la Antigüedad. Aprovechando la perspectiva diacrónica que ofrecen los nombres de lugar, se reconstituyen virtualmente ciertos elementos naturales y culturales del paisaje histórico de la comarca del Vinalopó mediante un análisis toponímico basado en elucidar la etimología de los nombres de lugar, en el método de observación de los rasgos geográficos de dichos lugares y en las fuentes históricas que se refieren a los mismos.

Palabras clave: toponimia; elementos naturales y culturales del paisaje; cuenca del Vinalopó.

\begin{abstract}
The Vinalopó basin, in the south of the Valencian Community (Spain), is composed of densely populated industrial towns that have been inhabited since ancient times. Taking advantage of the diachronic perspective offered by place names, certain natural and cultural elements of the historic landscape of the Vinalopó region are rebuilt by means of a toponymic analysis, based on decrypting the etymology of place names, by observing geographical traits in these places, and by consulting historical sources associated with them.
\end{abstract}

Key words: place names; natural and cultural elements of landscape; the Vinalopó Region.

\section{Introducción}

El objetivo de este artículo es la reconstrucción virtual, mediante el análisis toponímico, del paisaje de la cuenca del Vinalopó a partir de los nombres de lugar que actualmente designan sus núcleos de población. Con esta reconstitución se pretende poner en valor los elementos tanto culturales como naturales del paisaje de este territorio, con el fin de dar a conocer a los habitantes de la cuenca del Vinalopó el valor patrimonial que esconden sus topónimos principales.

\footnotetext{
1 Este es un trabajo inédito que deriva de la comunicación "Estudi semàntic sobre la toponímia dels pobles del Vinalopó", presentada en la XI Jornada d'Onomàstica de l'AVL i III Congrés de la Societat d'Onomàstica que se celebró en Elda y Petrer el 7 y 8 de abril de 2017.

2 Departamento de Geografía. Universitat de València, España. joan.membrado@uv.es

3 Departamento de Geografía. Universitat de València, España. emilio.iranzo-garcia@uv.es
} 
Los topónimos de los núcleos urbanos del Vinalopó (figura 1) describen una serie de elementos naturales y culturales de su paisaje histórico que hoy en día han sido olvidados o desvirtuados por la intensa urbanización o transformación agraria de dichas áreas, que antaño fueron de predominio rural. El estudio toponímico de dichos nombres de lugar nos ayuda a recuperar virtualmente aquellos rasgos naturales y culturales del paisaje -hoy desaparecidos- que propiciaron la creación de dichos topónimos.

La estructura de este artículo se compone de una primera parte introductoria de tipo teóricoconceptual acerca de la toponimia y su relación con el paisaje; a continuación, se explica el caso de estudio y la metodología seguida. Después, en el apartado de resultados y discusión, se aborda la semántica y el origen histórico-lingüístico de los principales topónimos urbanos de nuestra zona de estudio. Por último, en la conclusión se hace hincapié en el papel de los nombres de lugar como elementos que evocan un paisaje más o menos remoto que, en la actualidad, está en vías de desaparición o que ya ha sido completamente sustituido.

\subsection{La ciencia toponímica}

La toponimia, rama de la onomástica que estudia los nombres de lugar, es una disciplina de síntesis donde convergen diferentes campos de conocimiento que interactúan de manera complementaria (Tort, 2001). Poirier (1965) se refiere a las tres grandes ciencias auxiliares de la toponimia: historia, geografía y lingüística, y dentro de esta última especialmente la dialectología y la fonética. Dauzat (1971), por su parte, destaca la vertiente sociológica y filosófica de la toponimia, afirmando que la creación a lo largo de la historia de nombres para designar lugares nos permite comprender mejor las preocupaciones reales y místicas de las personas que los crearon. Dorion (1984) considera que los estudios toponímicos pueden emparentarse con la geografía, historia, lingüística, sociolingüística, psicolingüística y psicología social. La investigación toponímica se centra en el espacio geográfico (función toponímica) y en el tiempo histórico (memoria toponímica). El análisis morfológico y semántico de un topónimo, tanto su origen como su evolución, se emparenta con la lingüística (semántica, morfología). El análisis de grandes conjuntos de topónimos está vinculado a la sociolingüística. La psicolingüística destaca que un topónimo es un signo lingüístico y como tal de interés para la semiótica. La toponimia puede ser estudiada también como la expresión de una percepción de un lugar, lo que la relaciona con la psicología social. Querol (1995) defiende que la casuística que encierra la toponimia es tan variada que hay infinitas maneras de abordarla, sin que ninguna deba prevalecer sobre el resto. Aparte de los campos de conocimiento propuestos por Dorion, podemos añadir otros tan aparentemente alejados de la toponimia como la teledetección (Membrado-Tena, 2016).

El método clásico de análisis toponímico se centra en la recolección de nombres de lugar para detallar su origen y semántica, para lo cual es fundamental acudir a ciencias auxiliares como la geografía, la historia y la lingüística. Recientemente, sin embargo, desde el ámbito académico anglosajón se priman los estudios toponímicos que inciden en la psicología social -la percepción socio-espacial- que reflejan los nombres de lugar, producto del contexto ideológico e identitario que comporta cualquier proceso de toponimización (Rose-Redwood, Alderman y Azaryahu, 2010). Fijarse solo en la semántica o el origen de un topónimo minimiza el proceso social que va ligado al acto ideológico e identitario de toponimizar (Kearns y Berg, 2002).

La toponimia refuerza la identidad de un lugar de dos maneras. Por un lado, los topónimos funcionan como símbolos -igual que una bandera o un escudo- que designan un lugar; por otro, los nombres de lugar fortalecen los lazos emocionales con el espacio (Jordan, 2012). Los topónimos han de ser entendidos como parte de un proceso socio-espacial dinámico que está detrás de la identificación de las personas con un pasado que, en forma de historia y memoria, proporciona un vínculo afectivo para la vida e identidad de las personas en el presente (Fuchs, 2015).

Los estudios toponímicos que priman el aspecto socio-espacial sobre el etimológico se pueden centrar especialmente en áreas que fueron colonizadas o dominadas por políticas totalitarias. Las potencias coloniales o los regímenes autoritarios crearon o transformaron determinada toponimia como un mecanismo para consolidar el nuevo orden político dominante. Con la derrota y/o retirada de la metrópoli o del régimen, los nuevos gobernantes reemplazaron aquellos topónimos por otros que reivindicaban la nueva ideología (más o menos democrática, según los casos) y la identidad propia (cultura y lengua). 
Algunos de los nuevos estudios toponímicos que siguen el enfoque ideológico-identitario también tratan fenómenos recientes como la mercantilización toponímica (Mitchelson, Alderman y Popke., 2007; Light y Young, 2015): cada vez son más los nombres de lugar cuyos derechos son comprados y vendidos como mercancía, ya que son una forma de poder simbólico que crea distinción social entre las élites y las clases populares y que puede transformarse en capital simbólico (Bourdieu, 1991; Rose-Redwood, 2008). Cabe señalar que la imagen de poder que generan los topónimos ha desempeñado secularmente un papel notable en la economía política de promoción de un lugar.

La insistencia desde el ámbito académico anglosajón en primar el enfoque socio-espacial (ideológicoidentitario) es cuestionada por Whatmore (2002). Esta autora, aunque considera importante dicho enfoque, afirma que puede acabar diluyendo el interés conceptual por aquellos espacios donde los topónimos no se impusieron mediante políticas ideológico-identitarias, sino de manera pragmática, esto es, designando los elementos del paisaje del modo más significativo para los creadores de dichos topónimos, que necesariamente han de analizarse mediante el análisis lingüístico, histórico y geográfico. Este sería el caso de los topónimos de la cuenca del Vinalopó y, en general, de Europa, donde los nombres de lugar principales -creados en la Edad Media o en la Antigüedad-son meros descriptores del paisaje, a diferencia de lo que ocurre en general en la América urbana postcolombina, donde muchos topónimos -creados en época moderna o contemporánea- encierran una ideología que pretende naturalizar las estructuras del nuevo poder colonial.

Más allá del análisis lingüístico, histórico y geográfico, hay que decir que los topónimos de la vieja Europa también pueden ser analizados a partir de la perspectiva crítica. Por un lado, con muchos de ellos -especialmente con los creados por potencias fuertemente centralizadas- se pretendía consolidar el poder hegemónico del momento. Por otro lado, incluso los aparentemente pragmáticos topónimos de las edades Antigua y Media, que se limitan a describir los elementos del paisaje, en el fondo se asocian también a la ideología dominante de aquel momento, ya que el paisaje no es más que una manifestación colectiva de la ideología propia del momento histórico en que se forja (Di Giminiani y Fonck, 2015).

\subsection{Toponimia vs paisaje}

Los topónimos de la Antigüedad y del Medievo son los que predominan en nuestro caso de estudio: aunque de apariencia aséptica, no dejan de describir los elementos naturales y culturales de un paisaje que describe la ideología imperante en el momento de su fundación. La mayoría de los paisajes que describen los crípticos topónimos actuales del Vinalopó han desparecido en la actualidad. La ciencia toponímica, gracias a su conservadurismo lingüístico, y con la ayuda de la observación geográfica y la exploración histórica, se muestra como una potente herramienta para evocar aquellos paisajes extintos (Mallorquí, 2006; Tort, 2010). Si dichos paisajes no pueden recuperarse físicamente, al menos sí que pueden reconstruirse virtualmente, con la ayuda del análisis toponímico. Sauer (1956) considera que los topónimos son la cuarta dimensión de la geografía -la expresión del tiempo-, porque su estudio contribuye a la recuperación de la memoria de un paisaje históricos. Para Riesco (2010), el análisis diacrónico de los nombres de lugar es la forma de comprender la evolución de un paisaje secular que ya no existe.

La toponimia rescata el pasado mediante las diferentes capas y estratos de nombres acumulados a lo largo de la historia (Algeo \& Algeo, 2000), ya que es notablemente conservadora: por un lado, la evolución morfológica de los nombres de lugar muchas veces se detiene aunque los nombres comunes de su misma lengua continúen evolucionando; por otro, muchos sobreviven a la extinción local de la lengua en que fueron creados (como pasó con el ibérico, el latín y el árabe en la cuenca del Vinalopó), porque continúan siendo útiles para la designación de un enclave específico y diferente del resto de lugares, por mucho que carezcan de significado léxico en la nueva lengua del lugar. Los topónimos no funcionan, por tanto, como unidades léxicas normales. Poseen un significado referencial y por ello no necesitan evolucionar de acuerdo a la morfología de la lengua ni ser sustituidos en caso de que dicha lengua sea suplantada por otra. Gracias a este mecanismo de fosilización los nombres de lugares se convierten en una fuente inagotable de información histórica y geográfica que permite evocar un paisaje ya desaparecido.

Cuando hablamos de paisaje, cabe recordar que no solo nos referimos a un territorio físico, sino también a la percepción que de dicho territorio tiene las personas que lo observan. Nogué (2017) defiende que el paisaje es, a la vez, una realidad física y la representación que culturalmente se hace de ella; es el aspecto externo y visible de una determinada porción de la superficie terrestre y, al mismo tiempo, la per- 
cepción individual y social que genera; es una tangible geográfico y, además, su interpretación intangible. El Convenio Europeo del Paisaje afirma que un paisaje es "cualquier parte del territorio, tal y como es percibida por las poblaciones, cuyo carácter resulta de la acción de los factores naturales y humanos y de sus interrelaciones".

Algunos autores destacan el papel del carácter en la definición del paisaje, entendiendo este como la huella que secularmente ha imprimido la sociedad sobre la naturaleza, y que da sentido de lugar a cada territorio (Mata, 2014). El carácter, huella o memoria de un paisaje corresponde al espacio del recuerdo, de las vivencias, de los afectos; al espacio donde se ha fraguado la historia de un lugar y donde evolucionan los elementos que constituyen el imaginario colectivo. El paisaje-memoria explica la formación, consolidación y mantenimiento de identidades territoriales (Nogué, 2007). Es considerado como un registro de los métodos y prácticas sociales, políticas y culturales del pasado, donde todavía queda suficiente patrimonio histórico y cultural con el que trasladar la memoria a otras sociedades pretéritas que ocuparon el mismo espacio (Tesser, 2000). En el caso del Vinalopó, uno de los testimonios que preserva la memoria de lo que fue este rico y codiciado territorio de paso y de frontera se encuentra en su toponimia.

\section{Metodología}

Este análisis del origen histórico-lingüístico y semántico de los nombres de lugar de la cuenca del Vinalopó se centra principalmente en la toponimia mayor urbana. Se analizan 29 casos de toponimia mayor del valle del Vinalopó: casi todos correspondientes a los nombres de sus núcleos de población. Algunos autores se refieren a la artificiosidad de la distinción entre toponimia mayor y toponimia menor, o entre macrotoponimia y microtoponimia (Moreu-Rey, 1982). Para evitar el uso discutido de la fórmula toponimia mayor urbana o macrotoponimia urbana, hemos optado por designar este tipo de toponimia como de núcleos de población.

Las razones para analizar la toponimia de núcleos de población, y no otros tipos de nombres de lugar, son diversas. Por un lado, conforma un conjunto homogéneo de topónimos desde el punto de vista territorial, lo que permite establecer correlaciones entre unos nombres y otros, y entre los topónimos y el territorio. Por otro lado, la toponimia de núcleos de población posee un notable fundamento histórico, ya que suele ser la que se encuentra mejor documentada, debido a que el poblamiento es la base estructural sobre la que se organiza la vida de cualquier colectividad. No es extraño, por lo tanto, que las primeras referencias documentales acerca de los núcleos de población aquí estudiados se remonten a época medieval y, en algunos casos, a la Antigüedad. Por último, cabe añadir que, por el interés que despierta entre la población conocer la etimología de la localidad en que residen y que sienten como suya, la toponimia de núcleos de población ha sido abordada con carácter prioritario entre los especialistas (Tort, 2000).

En este trabajo utilizamos el método clásico de análisis toponímico, consistente en la recolección de nombres de lugar de los que se explica su origen histórico y su contenido semántico. Para llevar a cabo este estudio empírico se parte de tres ciencias principales: la geografía, la historia y la lingüística. Para averiguar la etimología de cada uno de los 29 topónimos aquí estudiados recurrimos en primer lugar a consultar una bibliografía variada. Tras dicha consulta cabe señalar que no siempre se encuentra consenso entre autores por lo que respecta a contenido semántico e, incluso, a origen histórico-lingüístico. No es infrecuente que, dependiendo de la fuente que se consulte, nos encontremos con que a un mismo topónimo se le asignen varios contenidos semánticos posibles. En ese caso, para elegir cual es el origen más probable entre los distintos significados, hemos recurrido a la observación geográfica o a las fuentes históricas. Si observamos que alguno de los significados atribuidos por la filología a un topónimo discutido se corresponde con un elemento natural o cultural plausible dentro de la comarca de estudio, optamos por dicho contenido semántico y evitamos las etimologías retorcidas o fantasiosas propias de algunos estudiosos (en especial con topónimos de origen árabe e ibérico).

Como hemos dicho, se analizan 29 nombres de lugar, entre los cuales hay cabeceras municipales, pueblos significativos sin municipio y, por último, el mismo topónimo Vinalopó, que da nombre a tres comarcas. Se trata de nombres de lugar -de origen lingüístico diverso (catalán, árabe, latino o ibérico)- cuyo significado original suele describir algún elemento, bien natural, bien cultural, de un paisaje alterado parcialmente o en su totalidad. El estudio de estos topónimos permite reconstruir virtualmente algunos paisajes de la cuenca del Vinalopó de épocas más o menos remotas. 
Por lo que respecta al origen histórico-lingüístico de los topónimos del Vinalopó, el periodo examinado en el presente artículo se extiende desde la época ibérica (con topónimos tan antiguos como Aspe, Elda o Elx); pasa por el periodo tardorromano (como Villena o Petrer); luego por el musulmán (como Monòver, Biar o Beneixama); y traspasa la conquista cristiana del siglo XIII (como en el caso de Salinas o el Pinós). Los topónimos descritos en este artículo están escritos en valenciano cuando la población es valencianoparlante y en castellano cuando es de habla castellana.

En cuanto al contenido semántico de los nombres de lugar de la toponimia de núcleos de población del Vinalopó, hemos creado dos bloques. El primero describe los elementos naturales del paisaje, entre los que encontramos de tipo orográfico (montañas, valles, llanos), hídrico (ríos, lagunas) y botánico. El segundo bloque analiza los elementos culturales, que dividimos en poblamiento concentrado (núcleos urbanos) y disperso (masías, alquerías, fundus), agrotopónimos y otros (hagiotopónimos, odónimos). Todos los nombres de lugar estudiados describen algún paisaje que era social y económicamente relevante en el momento de la fundación del municipio. Aunque en la actualidad han desaparecido o han dejado de ser esenciales para la economía local, estos paisajes continúan teniendo un notable valor identitario, ya que forman parte de la memoria de cada pueblo, y están cargados de valor simbólico -de carácter- para su gente.

El análisis toponímico se ha acompañado de un recuento estadístico (tabla 1) que resume los resultados obtenidos; de una fotografía (figura 3) que describe uno de los paisajes de nuestro estudio; y de una serie de mapas realizados mediante software ArcGIS (ESRI) que, por un lado, muestran algunos de los rasgos fisiográficos más significativos que dieron lugar a ciertos topónimos (figuras 2, 4 y 5) y, por otro, describen la situación general de nuestra comarca de estudio (figura 1), a la que dedicamos el siguiente epígrafe.

\subsection{Caso de estudio}

La cuenca del Vinalopó supera los $2.000 \mathrm{~km}^{2}$ (la mayor cuenca fluvial de la provincia de Alacant), si bien hay que decir que parte de la misma presenta carácter endorreico o semiendorreico. Engloba tres comarcas industriales densamente pobladas como son el Alto/Alt Vinalopó (Villena, Sax, Salinas, Biar, la Canyada, el Camp de Mirra y Beneixama) el Vinalopó Mitjà/Medio (Elda, Petrer, Novelda, Monforte, Aspe, Monòver, la Romana y el Fondó de les Neus) y el Baix Vinalopó (Elx y Santa Pola), además de un municipio de l'Alcoià (Banyeres), una porción de la Vall d'Albaida (sur del término de Bocairent y oeste de Fontanars dels Alforins) y en Castilla-la Mancha el municipio de Caudete (históricamente del Reino de Valencia), así como el sur del término de Almansa. Cabe señalar que las aguas de Crevillent (Baix Vinalopó) desaguan en la laguna del Fondo, donde llegan también las aguas del Vinalopó a través del Assarb (azarbe) de Civades; dicho canal posibilita una segunda desembocadura artificial del mismo río hacia el este, cruzando las salinas de Santa Pola, y llegando al mar. Hay que decir también que los municipios del Pinós, l'Alguenya y el Fondó dels Frares (Vinalopó Mitjà), así como su contiguo territorio murciano de habla valenciana (el Carxe), no forman parte de la cuenca del Vinalopó, aunque los hemos incluido en este estudio -junto con Crevillent- por proximidad geográfica y cultural.

Por lo que respecta a la orografía, la cuenca del Vinalopó ocupa en su mayor parte un valle que ha funcionado como corredor mediterráneo desde la Antigüedad, a pesar de encontrarse a cierta distancia del mar. Ello se debe al hecho de que entre Dénia y Alacant algunas de las sierras subbéticas llegan hasta la misma orilla de Mediterráneo, lo que siempre ha dificultado el trazado de una ruta litoral y ha priorizado el paso en cambio por el valle de Montesa, el llano dels Alforins y el valle del Vinalopó. Este último, además, permite conectar dicho corredor mediterráneo con la Meseta castellana y con la Andalucía occidental.

La cuenca del Vinalopó forma parte del gran accidente tectónico que se extiende entre Caudete y Elx, con dirección NNO-SSE, que ha seccionado transversalmente las alineaciones del Prebético y ha generado un área deprimida en forma de corredor que divide este sistema de orientación SO-NE, dejando al este las montañas de Alcoi y de la Foia de Castalla, y al oeste los amplios valles y corredores que conectan con el interior murciano (Ponce y Palazón, 1995). Entre las estribaciones montañosas prebéticas cabe destacar las sierras de Salinas (1.239 m), l'Ombria $(847 \mathrm{~m})$ y el Reclot $(1.053 \mathrm{~m})$, que presentan vertientes muy inclinadas y crestas agudas. La fractura trazada corta transversalmente esas alineaciones aprovechando la fosa tectónica por la que discurre, y es aprovechada por el río Vinalopó para encontrar una salida al mar.

La cuenca fluvial del Vinalopó, la más extensa de todo el mediodía valenciano, alberga cerca de medio millón de habitantes. Un desarrollo industrial de características endógenas fundamentado en el aprovechamiento de los recursos propios (donde destaca la producción de calzado), junto al mantenimiento y 
desarrollo de una rica agricultura (basada en la explotación de la viña para vino y para mesa, y de otros importantes cultivos de mercado), han posibilitado un desarrollo socioeconómico notable en esta comarca (Ponce y Palazón, 1995).

Desde el punto de vista histórico, el valle del Vinalopó formó parte de la Contestania ibérica, de cuya cultura se conservan numerosos vestigios materiales in situ, como en l'Alcúdia d'Elx o el Monastil de Elda, o en museos como el MAHE (Museo Arqueológico de Elx) y el MARQ (Museo Arqueológico Provincial de Alacant); como veremos en este artículo, algunos de sus más notables topónimos de núcleos de población son, desde el punto de vista lingüístico, de origen ibérico. Tras la conquista romana, que se inicia a finales del siglo III antes de Cristo, la lengua y cultura ibéricas fueron languideciendo y siendo sustituidas progresivamente por las latinas, que perduraron hasta el siglo IX, cuando se consuma la conquista árabe en estas tierras; del periodo de habla latina restan también numerosos ejemplos entre la toponimia de núcleos de población de la comarca. Con la conquista musulmana, el latín tardío es sustituido progresivamente por el árabe, y cuando llegaron los cristianos de los reinos del norte ya hacía décadas que había desaparecido; también del período de habla y cultura árabes han sobrevivido algunos notables topónimos de núcleos de población.

Figura 1. Mapa de la cuenca del Vinalopó

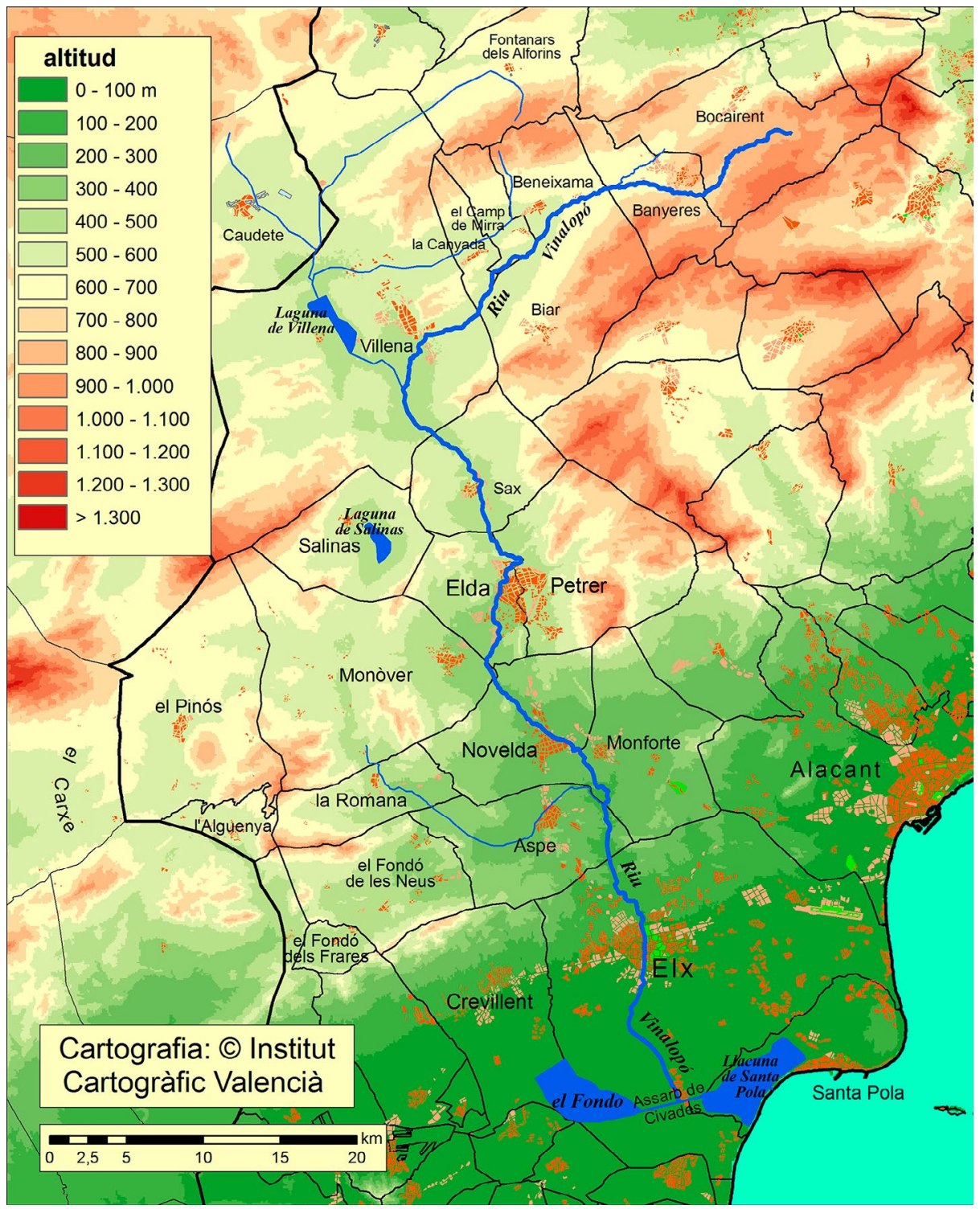

Elaboración propia. 
Con la conquista cristiana del siglo XIII, los pueblos de la cabecera del Vinalopó fueron anexionados al Reino de València, pero de Villena hacia el sur lo hicieron al castellano Reino de Murcia. Tras algunas décadas de disputas, la mayor parte de las tierras del Vinalopó se incorporaron a la llamada gobernación foral de Oriola (Orihuela), dentro del Reino de València. No fue hasta mediados del siglo XIV cuando las fronteras entre los reinos de València y Murcia quedaron definitivamente fijadas. En 1244 se había firmado el tratado de Almizra (o del Camp de Mirra) entre Castilla y Aragón, por el que la frontera sur del Reino de València la marcaban las poblaciones de Biar, Castalla y Xixona. Al sur de esta línea, las tierras conquistadas se reservaban a Castilla. Décadas después se produjo un conflicto dinástico en Castilla que enfrentó a Sancho IV con Alfonso de la Cerda. Este último ofreció a Jaime II de Aragón el Reino de Murcia a cambio de su apoyo. En 1296 el rey aragonés invadió este reino, pero el cambio de coyuntura en Castilla incitó a Jaime II a someterse a la sentencia arbitral de Torrellas (1304), que se completó con el acuerdo de Elx (1305), por los cuales todo el reino de Murcia, salvo el sector oriental, pasaría a Castilla (Mestre y Sabaté, 1998). Según los nuevos tratados, pasaron al Reino de València la histórica Governació d'Oriola, y también Villena, Sax, Jumilla y Abanilla. Medio siglo después, estas cuatro últimas poblaciones mencionadas se reintegraron a Castilla y se fijó el límite sur del reino valenciano. Villena y Sax volvieron a formar parte de la geografía valenciana a partir de 1836, cuando fueron incorporadas a la actual provincia de Alacant, que se había creado justo tres años antes (Membrado-Tena, 2013).

Por el hecho de encontrarse unidas físicamente, pero separadas entre las coronas de Castilla (Villena, Sax) y Aragón (el resto de la cuenca del Vinalopó), nuestra comarca de estudio fue una disputada zona de frontera en época medieval y eso se refleja en la abundancia de castillos de vigilancia (Villena, Biar, Sax, Petrer), pero también en su bilingüismo: algunos municipios han sido históricamente valencianoparlantes, como Elx, y otros castellanoparlantes, como Villena, mientras algunas zonas eran habitadas por moriscos de habla árabe. En época moderna, tras la expulsión a principios del siglo XVII de la comunidad musulmana, se produjo una variada repoblación, que dio como resultado que dos poblaciones tan próximas como Elda y Petrer (actualmente conurbadas) tuvieran como lengua el castellano y el valenciano, respectivamente, o que Aspe y Monforte formaran una isla castellanoparlante en un territorio valencianoparlante. Entre los topónimos de núcleos de población del Valle del Vinalopó encontramos una minoría de ellos que lingüísticamente son de origen catalán, y que se corresponden con las localidades de fundación más reciente, posterior a la conquista cristiana.

\section{Resultados}

Para describir y analizar el contenido semántico de los topónimos de núcleos de población del Vinalopó hemos agrupado los topónimos en función de si describen un rasgo físico (natural) del paisaje o bien uno humano (cultural) del mismo.

\subsection{Rasgos naturales del paisaje}

\subsubsection{Orografía}

El topónimo Sax (Saix para los pueblos valencianohablantes vecinos, y realizado como $S a(j)$, con la $j$ final muda pero que reaparece en el gentilicio sajeño/a, en la misma población y en los pueblos castellanohablantes cercanos) deriva del latín SAXUM, 'peña', ya que su castillo se halla en lo alto de un risco prebético. El relativamente cercano topónimo Xixona (del latín SAXONA), que describe también un castillo encaramado en un peñasco, tendría el mismo origen (Coromines, 1989-1997).

El topónimo Aspe (Asp, en valenciano) es de probable origen ibérico y podría significar 'bajo la peña' o 'al pie de la peña', refiriéndose a Aspe el Viejo. El antiquísimo topónimo Aspe es citado en las fuentes clásicas como IASPIS (Ptolomeo) o Aspis (Itinerario de Antonino) (Herrero, 1986). El topónimo parece prerromano, probablemente ibérico, y podría desentrañarse si admitimos la existencia de cierta afinidad -que no implica necesariamente relación filogenética- entre el vocabulario de dicha lengua y el del vasco. Alrededor del Pirineo, en zona de habla vascófona actual o histórica, encontramos topónimos similares: Aspa (Bearn); Aspi (s. XII Aispe y Azpe) y Azpa (Navarra); Axpe (Vizcaya); Azpeitia (Guipúzcoa); también Aspa (cerca de Lleida). Se puede interpretar como 'bajo la peña' o 'al pie de la peña', sobre la base del vasco (h)aitz 'peña', mientras la partícula - pe sería la postposición que indica 'debajo de', como en Azpeitia, donde beitia (peitia en determinados contextos fonéticos) significa 'de abajo' (Herrero, 1986, p. 14-16; Coromines, 1989-1997; Mitxelena, 1997). El actual pueblo de Aspe se encuentra sobre una zona que no 
es particularmente abrupta; sin embargo, Aspe el Viejo -donde se enclava el castillo histórico de Aspe (fortaleza almorávide del primer tercio del siglo XII) - sí que se ubica sobre una peña, bajo la cual debió existir antiguamente una partida denominada Aspe que había de dar nombre primero al castillo y, tras el traslado de este al valle, a la actual población homónima.

Monforte (castellanización del valenciano Montfort, 'monte fuerte') parece un orónimo sencillo, pero es, si cabe, más complicado que Aspe. Se trata, como hemos dicho, de una castellanización del valenciano Montfort, 'monte fuerte'. Y, sin embargo, Monforte no se ubica sobre un monte fuerte y abrupto, sino en un punto ligeramente elevado del valle del Vinalopó, aunque estratégico para el control del tránsito que lo recorre. Hay que decir que en la documentación medieval Monforte aparece con las formas Nompot y Nomport, que les conquistadores cristianos catalanoparlantes adaptaron a Montfort. Coromines (19891997) sugiere una compleja teoría para explicar la etimología de Nompot, que entiende como un nombre compuesto de la base vascoibérica nun 'cabra' y pot 'cumbre llana' (o sea, 'cumbre llana de las cabras'). No es descartable, a nuestro entender, un origen latino, partiendo de la forma Nomport, que aparece, alternando con Nompot, en varios documentos de los primeros siglos forales (Masià de Ros, 1994) y en la misma crónica de Muntaner (1325). Nomport podría ser un nombre compuesto de no(v) + port, donde la $v$ sería sustituida por una $m$ epentética, y donde nov podría referise a la vecina Novelda (Nova Elda) o simplemente a Novus ('nuevo'), mientras que port, de PORTus, 'paso entre montañas', se referiría a que allí en Monforte se encuentra el paso (llamado hoy el Portitxol) que separa el valle del Vinalopó del Camp d'Alacant (o Alacantí).

Un Camp (de Mirra) o 'campo' es un territorio llano, como es la comarca de Alacant o como es el Camp de Mirra, donde el alto valle del Vinalopó que viene de Banyeres es ancho (mide $8 \mathrm{~km}$ ) y todavía no se ha bifurcado en dos ramas (figura 4): una al norte donde está la Canyada, de $3 \mathrm{~km}$ de ancho; y otra al sur donde se encuentra Biar, de $4 \mathrm{~km}$.

Figura 2. Cuenca media-baja del Vinalopó

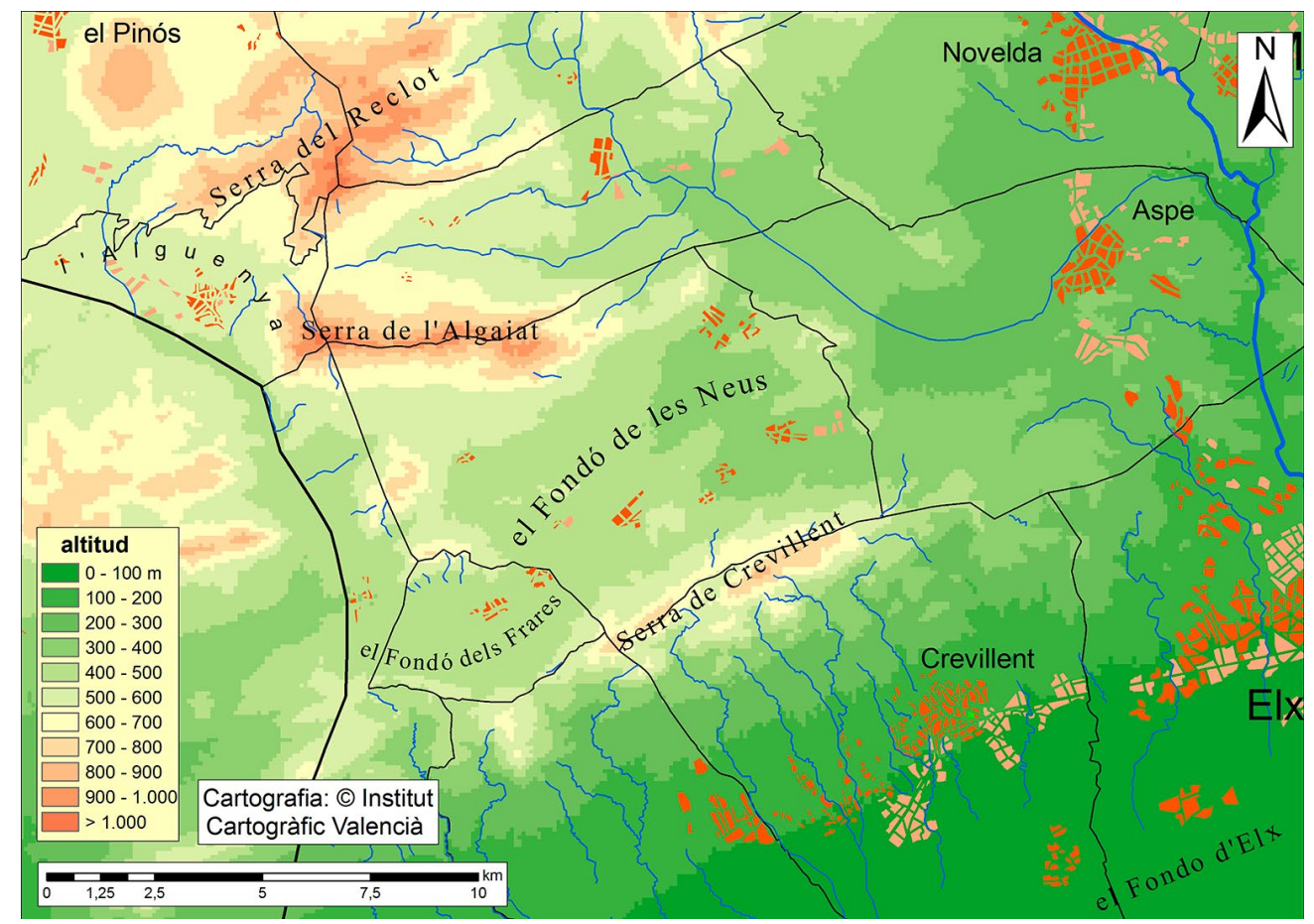

Elaboración propia.

El topónimo de l'Alguenya (antiguamente Alhenia) proviene del árabe al-hanya, 'curva de un valle' (Barceló, 2010, p. 50), ya que allí hay un pequeño valle subbético que gira bruscamente hacia el sudeste, paralelo a la fosa del Vinalopó, y flanqueado al este por las sierras del Reclot y de l'Algaiat (figura 2). Sobre el topónimo Alguenya (antiguamente Alhenia) podemos añadir que esta localidad está en el País Valenciano, pero justo en el límite con Murcia, y al otro lado de la frontera hay un pequeño caserío -que 
forma parte del Carxe (enclave valencianoparlante de Murcia)- llamado Canyada de l'Alenya (oficialmente 'Cañada de la Leña', término de Habanilla), donde Alenya es una variante más cercana a la forma antigua Alhenia.

En el sistema de corredores y sierras subbéticas del Vinalopó hay algunos topónimos que incluyen la palabra cañada, como por ejemplo el del municipio de la Canyada (de Biar) (figura 4). Las cañadas son relativamente estrechas, presentan forma cóncava, y están rodeadas de relieves en sus flancos que propician cierto desnivel por donde circulan las aguas.

El Valle del Vinalopó presenta una cuenca de difícil drenaje que se manifiesta a través de sus abundantes lagunas y fondons. En estas zonas el relieve no es convexo, sino cóncavo. Los fondons u hondones son zonas endorreicas donde se acumula el agua. Hay varios lugares así llamados: los municipios del Fondó de les Neus y del Fondó dels Frares (figura 2); el pueblo del Fondó de Monòver; el parque natural del Fondo de Elx-Crevillent; y diversas partidas denominadas Fondó o Fondura. Con lluvias intensas superiores a 100 litros estas zonas deprimidas se inundan con láminas de agua que pueden superar el metro (Olcina, Rico y Baños, 2007). A veces, las zonas presentan un endorreísmo acusado que pueden llegar a formar notables lagunas (Villena, Salinas), como veremos a continuación.

\subsubsection{Hidrografía}

Incluimos en este apartado el topónimo Salinas, que designa un municipio en cuya cuenca endorreica hay una laguna de la que se extraía sal hasta mediados del siglo xx.

El topónimo Banyeres parece describir un paraje donde es posible bañarse, como de hecho es el caso cerca de esta población, situada junto al nacimiento del Vinalopó, en lugares como la Font de la Coveta (figura 3), el Toll Blau o el Molí de l'Ombria.

Figura 3. Nacimiento del Vinalopó. Font de la Coveta (Bocairent), cerca de Banyeres

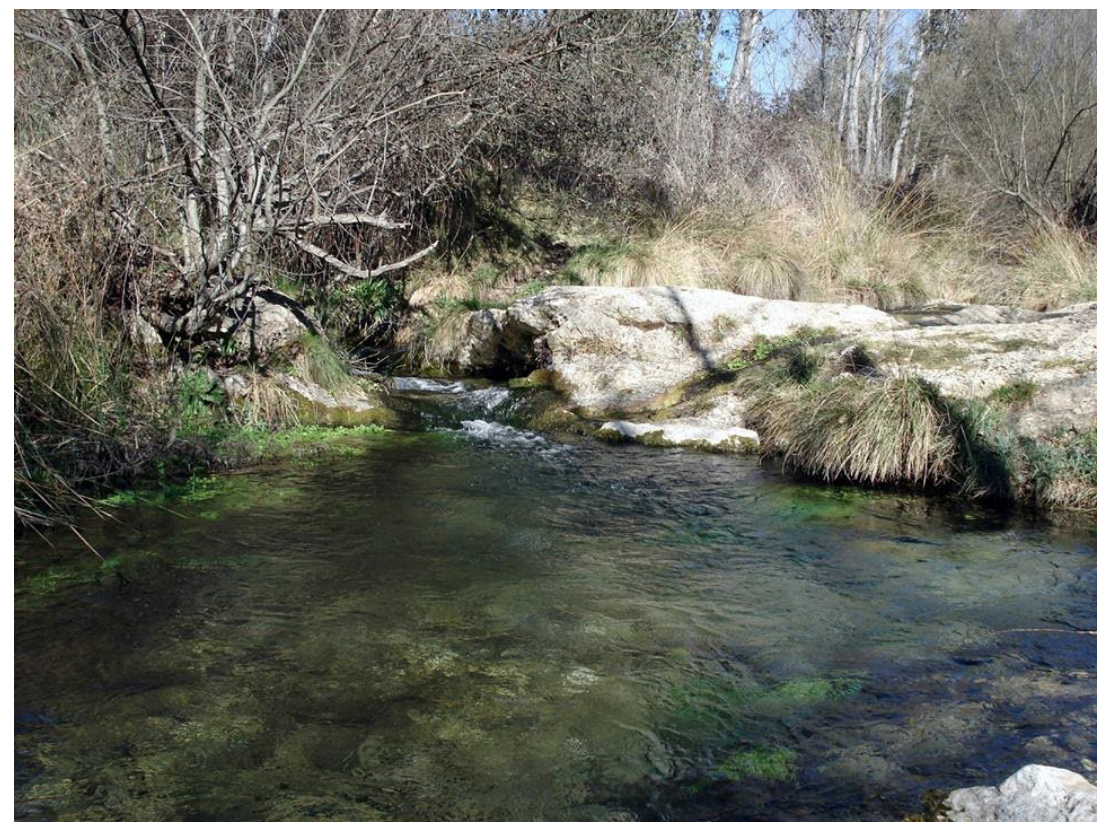

Fotografía de Antoni Martínez Bernat.

La semántica del topónimo de origen árabe Biar, 'los pozos' (Coromines, 1989-1997) es verosímil si tenemos en cuenta con la abundancia de acuíferos y manantiales que existe dentro del término de Biar.

También Fontanars, 'manatiales', es una zona rica en aguas, parte de las cuales se dirigen hacia el Vinalopó (figura 4).

Caudete podría ser también una 'cabeza de aguas' donde nacen algunos barrancos que aportan agua a la laguna de Villena, y de allí al río Vinalopó a través de la Acequia del Rey (Marco, 1998) (figura 4). Según Coromines (1989-1997) este topónimo proviene de CAPUT AQUAE, 'nacimiento del agua, fuente, 
manantial', que dio Qabdaq en árabe, Cabdet en valenciano y Caudete en castellano. Si nos fijamos en el topónimo valenciano de Caudete de las Fuentes parecería que estamos ante un topónimo tautológico ('fuente de las fuentes'). Esto refuerza la teoría según la cual Caudete o Cabdet significa 'fuente'. Sin embargo, algunos autores (Herrero, Cabanes y Ferrer, 1981) defienden que el origen del topónimo Caudete es CAPITETUM, derivado de CAPUt, 'cabeza, cerro o montículo'.

Figura 4. Cuenca Alta del Vinalopó

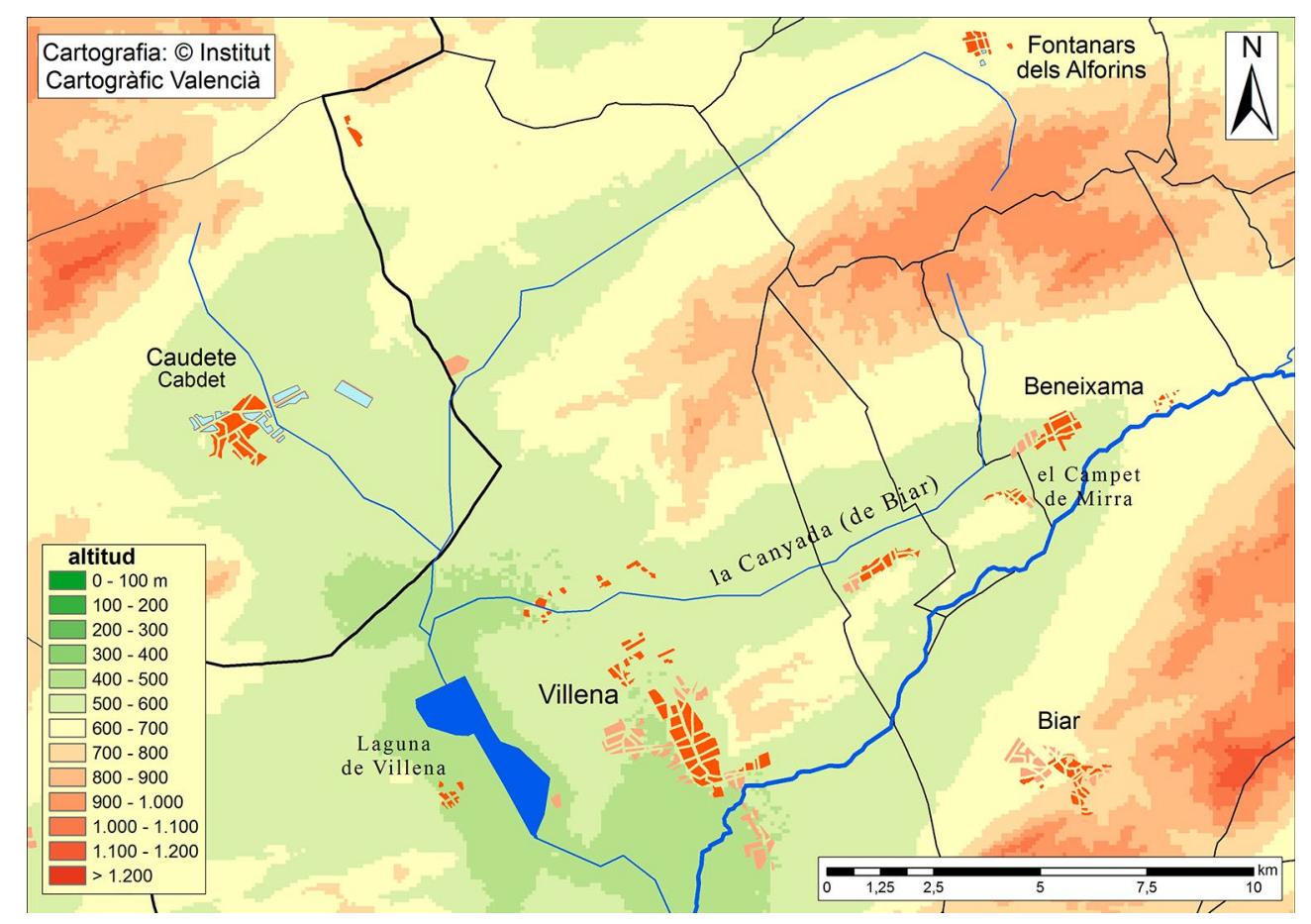

Elaboración propia.

Por lo que respecta al topónimo Vinalopó, presenta un origen complejísimo, y podría significar la 'peña sobre el río Río'. El topónimo Vinalopó, es el más complejo de todos los que aquí se analizan. Se puede descomponer en cuatro partes: Vin $+\mathrm{al}+\mathrm{op}+\mathrm{on}$. 'Vin' podría derivar del árabe Ibn, 'família, clan, lugar de', y 'al' sería el artículo árabe. Sin embargo, no es descartable un origen latino anterior, PINNA, 'peña' (en referencia al montículo donde se ubica el actual castillo del Vinalopó), adaptado fonéticamente al árabe como Bina (ya que esta lengua no posee la $p$, y tiende a pronunciarla sonorizada como $b$ ); sumándole el artículo árabe al, tendríamos Bin-al. En cualquiera de los dos casos los repobladores cristianos debieron confundir bin con 'vino', lo que dio lugar a la forma vin + al, tal como pasó con el topónimo Vinaròs (s. XIII Binalaròs).

En cuanto a la partícula op, y sus variantes gráficas o fonéticas $o b, u p, u b, a b$ y ap (la forma Vinalopó alterna en documentos antiguos con la forma Vinalapó), se trata de apelativos indoeuropeos para referirse a un 'río' (Villar, Prósper, Jordán y Fernández, 2011), que aparecen en topónimos tan separados como Danubius, 'Danubio', Ob o Obi (río siberiano), Corduba (Córdoba, junto al Guadalquivir), Úbeda (cuyo primer emplazamiento también estaba junto al mismo río bético), OnuBa (Huelva, entre los ríos Tinto y Odiel) o SAlduba (Salduie o Salduvia, actual Zaragoza, junto al Ebro). De hecho, los hidrónimos formados con la terminación llop o llup podrían no derivar del animal llop, 'lobo', sino de las formas indoureuropeas op/up, como en el caso de Benillup (junto al Barranc del Sofre, afluente del Serpis), Benilloba (junto al Riu de Penàguila o Frainos, también afluente del Serpis), Benalup (al lado del río Barbate), Guadalupe (junto al río homónimo), o incluso las formas Cantallops, Cantalobos y Chanteloup (topónimos frecuentes en Europa occidental).

Otra partícula hidronímica frecuente en la Península Ibérica es an, que aparece en topónimos como Guadiana, Riu Anna (Plana de Castelló) o Albufereta de Anna (Canal de Navarrés). Dicha partícula vacila entre las vocales a/o, y podemos encontrar también la forma hidronímica on en topónimos como ONUBA 
(Huelva) (Villar, 2000). Por tanto, la forma on (apocopada en ó en el caso del Vinalopó siguiendo las reglas fonéticas habituales del catalán) podría tratarse también de un apelativo indoeuropeo que significaría 'río' y que aparece en ríos ibéricos como Ebrón, Jalón, Seguró o Xaló. Las formas hidronímicas an y on (también la variante un) pueden encontrarse también en nombres de lugares tan remotos entre sí como las Islas Británicas, donde hay varios ríos Avon (tanto av como on significarían 'río') y el Mar Negro, en el que desembocan grandes ríos europeos como el Danubio (Donau/Dunav/Dunai), Don (y su afluente Donets), Dniéper (ant. Danapris) o Dniéster (ant. Danastris), donde las formas on y an vienen precedidas de $d$, y derivarían de una forma indoeuropea dānu que significa 'el río' (Mallory y Mair, 2000). La forma hidronímica on/un, a veces seguida de d o de $n$, está presente también en topónimos como Onda (junto al Riu Sonella), Ondara (Riu Girona), Ondara (río de la Catalunya occidental, entre las comarcas de Segarra y Urgell), Girona (Gerunda) y su río Onyar (latín undarius), o Garona (Garunna). (Vinal) op + on parece funcionar como un topónimo tautológico ('el río río'), de la misma manera que Avon o OnUBA, si bien este último presenta sus dos apelativos en orden inverso $(o n+u b)$ (Villar, 2000).

\subsubsection{Vegetación}

En este grupo cabe mencionar el topónimo el Pinós (Pinoso, 'abundante en pinos'). Este municipio se halla en la cara norte de la sierra del Reclot (figura 2), que es la más abrupta y sombría y propicia para la vegetación arbórea, que debía ser tan espesa como la del cercano Carrascal de Salinas, también orientado al norte. Actualmente la cara norte de la sierra del Reclot ha sido en gran parte destruida a causa de la explotación del abundante mármol existente en la misma.

El topónimo La Encina (término de Villena) sería otro ejemplo de vegetación arbórea para designar un núcleo urbano, conocido por ser un nudo ferroviario de primer orden.

El topónimo Carxe (Carche) derivaría del latín CAREX, CARICIS y habría dado también la forma castellana 'carrizo'. Tanto carrizo como carxe se refieren a una planta gramínea que crece cerca del agua. Ya hemos comentado como la cuenca del Vinalopó (y la adyacente del río Segura) está salpicada de zonas húmedas semiendorreicas donde crecería este tipo de vegetación (cf. partida del Carrizal, Villena).

\subsection{Rasgos culturales del paisaje}

\subsubsection{Poblamiento concentrado y disperso}

Entre los topónimos descriptores del poblamiento hay que diferenciar los que designan un núcleo de población concentrado de aquellos que se refieren a un núcleo disperso (masía, caserío, alquería).

Dentro del grupo de poblamiento disperso podemos destacar, en el área del Vinalopó, ciudades como Elx, Elda y Novelda. Tanto Elx (Ilici) como Elda (Ello) derivarían del ibero ili, 'ciudad, pueblo'. El topónimo Novelda podría tratarse de un nuevo asentamiento fundado por gente del valle de Elda (Nova ELLO > Novelda). Vamos a analizar, a continuación, los tres casos.

Elx (Ilici) y Elda (Ello) derivarían del ibero ili, 'ciudad, pueblo', forma que aparece también en el paleovasco. Ili e iri son variantes guipuzcoanas y navarras (cf. Iriberri, Irún, Iruñea) de la palabra que significa 'poblado', mientras que uli y uri son formas vizcaínas y alavesas del mismo vocablo (cf. Uribarri) (Llobregat, 1991; Pocklington, 2010). La forma il(i) aparece, además de en ILICI (Elx), en otros topónimos ibéricos urbanos de la Península como Iliturgi (Andújar), Iliberri (Ilbīra, Elvira, barrio de Granada), IlerDA (Lleida) o Iluro (Mataró); tanto Ildum (tal vez Vilanova d'Alcolea, el Maestrat) como (Ad) Ello (Elda) pueden ser interpretadas como variantes de il(i).

La Colonia Iulia Ilici Augusta se hallaba en el actual yacimiento de l'Alcúdia, a unos cuatro kilómetros al sur de la actual ciudad de Elx, que se originó en época musulmana. Ilici es la suma de ili, 'ciudad' + -ci, que sonaba -ki. Esta terminación reaparece en otros topónimos iberorromanos como Urci (Villaricos, Cuevas del Almanzora), 'lugar de agua, charca': ur 'agua' + ki (lugar); o Iliturgi (Andújar), 'poblado del lugar de la fuente': ili (ciudad) + itur (fuente) + ki/gi (lugar) (Pocklington, 2010).

Respecto a Elda, que existió una ciudad romana de nombre Ello queda fuera de duda, como muestran algunos itinerarios romanos: el Antoniano menciona la mansio AD Ello. El Anónimo de Rávena (s. VIII) alude a Eloe, si bien en el Libro v escribe Edelle (Arasa, 2008-2009). La Geografía de Guido, inspirada seguramente en la fuente anterior, escribe también Edelle (Herrero, 1986). El lugar de Ello habría estado cerca de la actual Elda, seguramente en el yacimiento iberorromano del Monastil, en un alto junto 
al Vinalopó. El lugar AD ELLo mencionado en los itinerarios podría ser una posta de la vía romana que comunicaba la Vía Augusta con Cartagena a través del Valle del Vinalopó, ya que dicho topónimo, al ir encabezado por $\mathrm{AD}$, indica la existencia en aquel punto de un camino secundario que conduciría a ELLO (el Monastil) (figura 5). Los primeros escritos cristianos tras la conquista medieval usan la grafia Etla o Ella (pronunciado El.la) que coexistió durante algunos siglos con la forma alternativa Elda, hasta que esta última se impuso definitivamente a partir del siglo xvI.

El topónimo mixto (latino e ibero) Novelda aparece citado por fuentes árabes como Niwala (XII) y por fuentes cristianas (siglos XIII y XIV) como Noella y Novella (pronunciados Noel.la y Novel.la). Convive con la forma Novelda hasta que esta última se impone durante la edad Moderna (Coromines, 1989-1997). Seguramente se trata de un asentamiento fundado por gente del valle de Elda. Mientras que Ello (Elda) es, como hemos dicho, una fundación prerromana, Novelda es de origen romano o tardorromano, lo que podría explicar que su nombre se inicie con el morfema latino nov- (de novus) (Montoya, 1982).

En el grupo del poblamiento disperso, cada alquería o masía es descrita normalmente mediante un antropónimo: el nombre del propietario. No es este, sin embargo, el caso del topónimo (el Camp de) Mirra, que proviene de Mizrà 'granja, masia' (antiguamente Almizrà, Almirra, cf. Almiserà) (Barceló, 2010), pero sí del resto de topónimos que estudiaremos y que describen un poblamiento disperso.

Dentro de este grupo cabe citar también ciudades hoy notables, como Villena o Crevillent. Tanto Villena como Crevillent y Bocairent son antropónimos que derivarían de propietarios de una villa tardorromana o Fundus: la villa belliana, propiedad de Bellius (Herrero, 1986, p. 50), y los Fundus * CARvilianu y * Voconianu pertenencientes a sendos propietarios * CARviliu (Herrero, 1986: 46) y *Voconiu (Coromines, 1989-1997).

Por lo que respecta al topónimo tardolatino Villena, hay que señalar que en 1100 aparece citado en la Historia Roderici bajo las formas Belliana y Belliena. Las formas Balyana (XII) y Bilyana (XIII) proceden de fuentes árabes. En fuentes cristianas del siglo xil encontramos Billena, en textos en valenciano (esta forma con $b$ perdura -alternando con la forma con $v$ - en esta lengua hasta el siglo xviI), mientras que Villena empieza a usarse tempranamente en textos castellanos, debido a la influencia analógica de la palabra común 'villa' (Herrero, 1986).

En cuanto al también topónimo tardolatino Crevillent, hay que señalar que poco después de la conquista cristiana, en 1263, recibía la denominación de Crevillén o Crivillén (sin la -t final). El elemento fónico añadido $t$ se debe a una ultracorrección por influencia analógica de adjetivos y participios de presente en -ent (Herrero, 1986), propios del catalán. El mismo fenómeno fónico se produjo en Bocairén (Bocairent).

Con la llegada de los musulmanes se consolidó en Xarq al-Ándalus un agrosistema de regadío donde proliferó la unidad de explotación y de habitación dispersa llamada alquería (Iranzo-García, 2014). Los antropónimos árabes se corresponden normalmente con nombres de alquerías, entre los cuales abundan aquellas cuyo topónimo empieza por Ben-, derivado de ibn, 'familia, clan', como en Beneixama, derivado de Xamah (Barceló, 2010).

\subsubsection{Agrotopónimos y otros}

Por lo que respecta a los agrotopónimos, cabe destacar els Alforins (partida y municipio de la Vall d'Albaida y partida de Villena, llamada allí Los Alhorines), derivado del árabe al hurī, 'el granero' (Barceló, 2010), por el notable cultivo de cereales que allí se da.

El topónimo La Romana deriva del árabe rummana, 'granada (fruta)', 'granado (árbol)' (Coromines, 1989-1997).

Por su parte, el topónimo Monòver parece derivar del árabe munáwwir, 'florido, floreciente' (cf. la Florida, Florencia), participio del verbo náwwara 'florecer' (Coromines, 1989-1997). Hasta el siglo XIX, la calle Mayor o carrer Major marcaba el límite urbano de Monòver; más abajo quedaban los fértiles huertos regados con agua que provenía de la aldea de Xinorla, cuya fertilidad tal vez dio nombre a la población.

El aparente hagiotopónimo tardorromano Santa Pola, antes conocido como Portus Illicitanus, debió formarse, según Mas (1991), durante la alta Edad Media, y derivaría de SANCTA PAUlA. Así lo corrobora Coromines (1989-1997), que afirma que este topónimo es tardorromano y, por lo tanto, anterior a la conquista sarracena. En las crónicas musulmanas aparece como Sant Bul (Crónica de al-Bakri, s. xI) (Sánchez, 1986) y como Santa Bula (s. xv). Según la tradición, el apóstol San Pablo habría desembarcado en la Illa Plana (Tabarca), y el nombre medieval de dicha isla habría sido San Pablo (Serrano, 2015) de 
donde derivaría el nombre de la vecina Santa Pola, a solo $8 \mathrm{~km}$ de la Illa Plana. Román (2004) sugiere que, en realidad, el origen del topónimo Santa Pola serían los paLus o lagunas que caracterizan la geografía física de su término municipal. Palus se habría confundido con PAulus, quizá por la influencia de aquella tradición del desembarco de San Pablo, y habría formado Polus, que en su forma feminizada -habitual para referirse a las poblaciones- habría resultado en Pola.

Por lo que respecta al topónimo Petrer, parece derivar de PETRARius, 'cantera', 'lugar de donde se extrae la piedra'. Epalza (1988) cree que este topónimo se refiere en realidad a un notable camino romano empedrado (figura 5), del cual se sacaban losas para construcciones diversas. Aúna, por lo tanto, un componente natural (la piedra en sí) y otro cultural (la piedra en tanto que usada para obras varias). Epalza (1988) cree que este topónimo se refiere al ramal de la Vía Augusta (calzada empedrada) que se dirigía hacia Cartagena por el valle del Vinalopó (figura 5). Otros topónimos similares ubicados junto a calzadas notables son el manchego Petrola, entre Almansa y Chinchilla, o los valencianos Petrés (camino de Sagunt a Zaragoza) y Patraix (entre València y Xàtiva). Por lo tanto, según Epalza, Petrer sería un odónimo (nombre de lugar que describe vías de comunicación).

Figura 5. Ramal de la Vía Augusta a su paso por la cuenca del Vinalopó

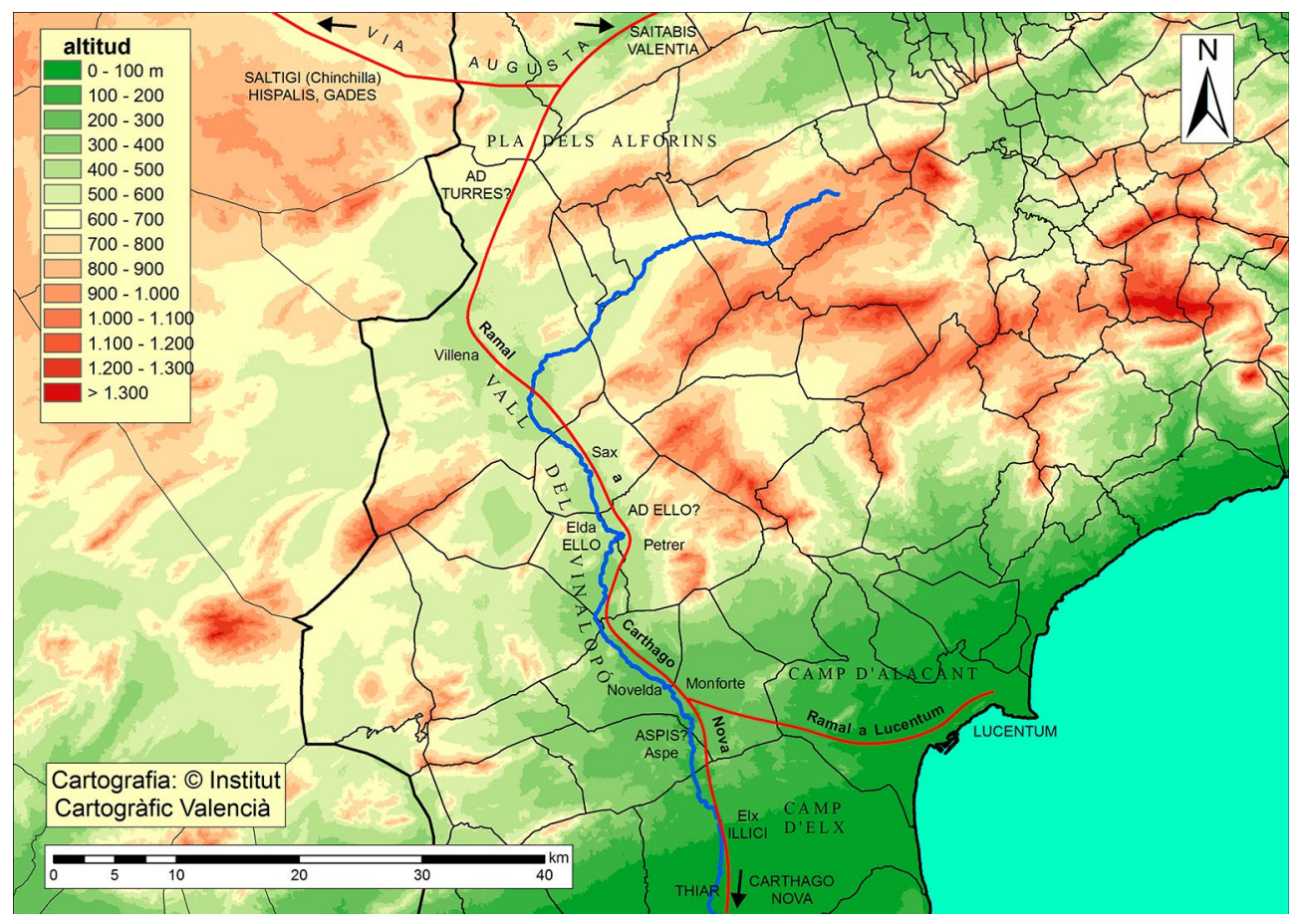

Fuente: Poveda (1991). Elaboración propia.

\subsection{Resumen de resultados}

De los 29 topónimos de núcleos de población analizados 17 describen elementos naturales del paisaje ( 7 de relieve, 6 de agua, 3 de vegetación). No es sorprendente el predominio de estos elementos físicos, teniendo en cuenta el sobresaliente relieve de orientación bética que atraviesa la cuenca del Vinalopó de SE a NO y las escasas aguas que hay en dicha cuenca, que convierten a este líquido en un bien escaso y preciado. Como hemos visto a lo largo de este epígrafe, estos rasgos físicos del paisaje han sido empleados como lugares estratégicos de defensa y vigilancia del territorio, para abastecimiento de agua o de leña, o para ser explotados como canteras, salinas, u otras materias primas con las que comerciar y mejorar así la calidad de vida de sus pobladores.

De los 29 topónimos urbanos analizados 13 describen rasgos culturales del paisaje ( 5 de poblamiento disperso, 3 de poblamiento concentrado, 3 agrotopónimos, 1 hagiotopónimo y 1 odónimo). Dichos topónimos describen un paisaje histórico donde abundaba el poblamiento disperso a partir de pequeñas explotaciones agropecuarias (masías, alquerías, FUNDUs), pero también algún notable poblamiento con- 
centrado existente desde la Edad Antigua. Los habitantes de estos poblados fueron capaces de prosperar gracias a la explotación de sus recursos naturales inmediatos y a su ubicación estratégica junto a las vías más importantes y en zonas de contacto entre ambientes naturales diversos, que propiciaban el intercambio comercial entre ámbitos agrarios complementarios.

Tabla 1. Origen lingüístico y semántico de los topónimos de núcleos de población del Vinalopó.

\begin{tabular}{|l|l|l|l|l|l|l|}
\hline \multirow{2}{*}{ topónimo } & \multicolumn{3}{|c|}{ natural } & \multicolumn{3}{c|}{ cultural } \\
\cline { 2 - 7 } & orografía & hidrografía & botánica & poblamiento & cultivos & otros \\
\hline prelatino y anterior & Aspe & Vinalopó & & Elx Elda & & \\
\hline latino & Sax Monforte & Caudete & Carxe & $\begin{array}{l}\text { Novelda Crevillent } \\
\text { Bocairent Villena }\end{array}$ & & Sta. Pola Petrer \\
\hline árabe & Alguenya & Biar & & Mirra Beneixama & $\begin{array}{l}\text { Alforins Romana } \\
\text { Monòver }\end{array}$ & \\
\hline Catalán y castellano & $\begin{array}{l}\text { Camp } \\
\text { Canyada Fondó }\end{array}$ & $\begin{array}{l}\text { Salinas Banyeres } \\
\text { Fontanars }\end{array}$ & Pinós Encina & & & \\
\hline
\end{tabular}

Elaboración propia.

\section{Discusión}

Para obtener los resultados de este artículo nos hemos basado en el método clásico de análisis toponímico, centrado en la recolección de nombres de lugar para detallar su origen y semántica. Dicho método se basa en los tres campos de conocimiento referidos en la introducción: historia, geografía y lingüística. La lingüística es una ciencia clave para elucidar el origen semántico de los topónimos aquí estudiados, pero sin un conocimiento previo del contexto geográfico e histórico de nuestro caso de estudio, el desciframiento de un topónimo puede ser mucho más costoso e incluso puede dar lugar a equívocos.

$\mathrm{Al}$ analizar desde el punto de vista lingüístico algunos topónimos, se muestra su extrema complejidad, derivada normalmente de su origen antiquísimo. El caso más notable aquí estudiado es el de Vinalopó, que puede descomponerse en cuatro partes: Vin + al + op + on. Además de complejo, parte de este topónimo es probablemente tautológico. Los topónimos tautológicos no son en absoluto infrecuentes (hemos mencionado en este artículo el ejemplo de Caudete de las Fuentes, aparte del caso de Vinalopó). Cuando un pueblo que habla una determinada lengua invade y ocupa un territorio habitado por otro pueblo que habla una lengua distinta, adopta sus topónimos fluviales como meros elementos referenciales, sin contenido semántico, y les añade el nombre común que en su lengua significa 'río', y así se forman los topónimos tautológicos. Puede parecer paradójico en el caso de Vinalopó que los dos apelativos para 'río' sean de naturaleza indoeuropea. Esto se explica porque el proceso de indoeuropeización de la Península Ibérica debe verse como algo complejo y dilatado en el tiempo, con lo que sería posible que unos pobladores indoeuropeos se encontraran con topónimos creados por otros pobladores también indoeuropeos, pero muy anteriores o sin relación directa con ellos, y por lo tanto dichos topónimos no resultaran transparentes para los recién llegados (Villar, 1995).

Respecto al método más crítico y novedoso de análisis toponímico, que incide en la percepción socio-espacial que reflejan los nombres de lugar, cabe destacar que cada topónimo, por muy aséptico y pragmático que parezca, está describiendo el contexto ideológico propio de la época en que fue creado. Si los pobladores de Sax decidieron llamarlo así fue porque se fijaron en la ventaja estratégica que suponía crear una fortaleza en lo alto de una peña desde la que se controla el tránsito de la parte norte del Valle del Vinalopó. Si los de Banyeres lo llamaron así, fue para marcar la existencia de unas charcas que podían ser aprovechadas para consumo personal o agrícola en un entorno natural caracterizado por la sequedad durante la mayor parte del año. Y lo mismo se puede decir de Biar, donde la abundancia de fuentes destacaba por la rareza y la conveniencia de las mismas en la comarca del Vinalopó. Si al Pinós lo llamarón así fue para indicar la abundancia de coníferas, y con ellas de madera, caza y otros usos. Si Salinas fue así designada estaba clara la intención de sus fundadores de aprovechar y explotar la sal que allí era presente, o el carrizo en el caso del Carxe. Si a Elda o a Elx las bautizaron como 'ciudades' y no como 'aldeas' era porque pretendían ser las cabezas urbanas visibles de un amplio territorio, tal vez en disputa entre ambos 
centros. Los lugares que derivan de nombres de persona, como Villena o Crevillent, expresaban una propiedad desde donde un señor feudal ejercía su dominio, pero también su protección.

A este respecto cabe remarcar el papel de los topónimos como una forma de poder simbólico, donde la semántica del nombre está describiendo algunos rasgos naturales y culturales del paisaje, de carácter positivo (agua, fuentes, vegetación, recursos minerales, protección natural, protección señorial...), que ayudan a la promoción económica de un lugar. Una vez desprovistos de significado semántico, los topónimos siguen funcionando como símbolos (referenciales) que refuerzan la identidad de un lugar.

\section{Conclusiones}

A tenor de los resultados obtenidos y de su discusión, se puede concluir que a partir del análisis toponímico de un territorio es posible, por un lado, evocar sus paisajes históricos y, por otro, remarcar el valor identitario de los mismos para dicho territorio. El método analítico de la toponimia aquí usado para reconstruir y revalorizar paisajes históricos aprovecha el conservadurismo de los topónimos (en especial de los de núcleos de población), y se basa en el desciframiento e interpretación etimológica de los nombres de lugar, en la observación geográfica de dichos lugares, y en las fuentes históricas que hacen referencia a los mismos.

El conservadurismo de los topónimos es clave para rememorar un paisaje histórico, el cual fue formado a partir de una serie de elementos naturales que fueron explotados históricamente por las personas que lo habitaban. Cuando los primeros pobladores de cualquier territorio encontraron una serie de recursos naturales plausibles de ser explotados y decidieron quedarse en él, trataron de organizar dicho territorio a su conveniencia y, para hacerlo de la manera más efectiva y pragmática posible, su primera tarea fue designar cada lugar significativo con un nombre. De esta manera surgen los topónimos, que son un reflejo de los intereses materiales de las personas que los crearon por primera vez y de la lengua de dichas personas. La resistencia y obstinación de muchos topónimos a su desaparición, por mucho que cambien las condiciones culturales, sociales y económicas de un territorio, los convierte en una fuente primordial para la evocación de paisajes históricos.

Como hemos dicho anteriormente, el carácter del paisaje resulta de la acción de los factores naturales y humanos y de sus interrelaciones. Esta relación de las personas con sus recursos naturales inmediatos modela el territorio y deja una huella que imprime carácter a un paisaje que, aunque desaparezca, siempre formará parte de la memoria de aquel territorio. A menudo, especialmente en comarcas fuertemente urbanizadas, el paisaje histórico ha quedado tan desvirtuado que solo conserva sus topónimos para evocarlo. La huella de aquel paisaje evocado por un topónimo debería estar presente en el imaginario colectivo, ya que forma parte de la historia y de la geografía de un territorio, y explica la formación y consolidación de su identidad.

\section{Referencias}

Algeo, J. \& Algeo, K. (2000). Onomastics as an interdisciplinary study. Names, (48, 3-4), 265-274. https:// doi.org/10.1179/nam.2000.48.3-4.265

Arasa, F. (2008-2009). La Vía Augusta en el País Valenciano. Anas, (21-22), 341-381.

Barceló, C. (2010). Noms aràbics de lloc. València: IIFV-Bromera.

Bourdieu, P. (1991). Language and Symbolic Power. Cambridge: Harvard University Press.

Coromines, J. (1989-1997). Onomasticon Cataloniae. Els noms de lloc i noms de persona de totes les terres de llengua catalana. Barcelona, Curial Edicions Catalanes \& La Caixa, vil vol.

Dauzat, A. (1971). La toponymie française. París: Payot.

Di Giminiani, P. y Fonck, M. (2015). El paisaje como proceso de vida: experiencias de domesticación del bosque en el sur de Chile. Revista de Geografía Norte Grande, (61), 7-24. http://dx.doi.org/10.4067/ $\underline{\text { S0718-34022015000200002 }}$

Dorion, H. (1984). Les relations entre la toponymie et les autres sciences sociales. En: 450 ans de noms de lieux français en Amerique du Nord (pp. 103-108). Québec: Les Publicacions du Québec.

Epalza, M. (1988). El Significat etimològic de Petrer: camí empedrat. Societat d'Onomàstica. Butlletí interior, (31), 10-11. 
Fuchs, S. (2015). History and heritage of two Midwestern towns: a toponymic-material approach. Journal of Historical Geography, (48), 11-25. https://doi.org/10.1016/j.jhg.2015.01.003

Herrero, A. , Cabanes, A. y Ferrer, R. (1981). Documentos y datos para un estudio toponímico de la Región valenciana. Valencia: Artes gráficas Ferrando.

Herrero, A. (1986). Toponimia premusulmana de Alicante a través de la documentación medieval (II). Anales de la Universidad de Alicante. Historia Medieval, (4-5), 9-48. https://doi.org/10.14198/ medieval.1986.4-5.01

Iranzo-García, E. (2014). La Huerta de Valencia. Incertidumbre para un paisaje cultural ancestral. En F. Molinero (coord.), Atlas de los paisajes agrarios de España (pp. 512-532). Madrid: Ministerio de Agricultura, Alimentación y Medio Ambiente.

Jordan, P. (2012). Place names as ingredients of space-related identity. Names and Identities, (4-2), 117131.

Kearns, R. \& Berg, L. (2002). Proclaiming place: towards a geography of place name pronunciation. Social and Cultural Geography, (3), 283-302. https://doi.org/10.1080/1464936022000003532

Light, D. \& Young, C. (2015). Toponymy as Commodity: Exploring the Economic Dimensions of Urban Place Names. International Journal of Urban and Regional Research , (39-3), 435-450. https://doi. org/10.1111/1468-2427.12153

Llobregat, E. A. (1991). Els noms pre-romans en «ili- ilu-» a les terres hui valencianes. En: Colomina, J. i Alemany, R., Actes del catorzè Col-loqui general de la Societat d'Onomàstica (segon d'onomàstica valenciana), Alacant, 644-651.

Mallorquí, E. (coord.) (2006). Toponimia, paisatge i cultura. Els noms de lloc des de la lingüística, la geografia i la historia. Col.lecció fonts, 4.

Mallory, J. P. y Mair, V. H. (2000). The Tarim Mummies: Ancient China and the Mystery of the Earliest Peoples from the West. Londres: Thames and Hudson.

Marco, M. (1998). 'Venida de agua de lluvia' en 1571: endorreísmo y avenamiento precario en el término de Villena (Alicante). Investigaciones geográficas, (20), 163-180. https://doi.org/10.14198/ INGEO1998.20.04

Mas, A. (1991). Toponímia històrica de Santa Pola. En: Actes del XIVè Colloqui General de la Societat d'Onomàstica (pp. 657-670). Alacant: Generalitat Valenciana.

Masiá de Ros, Á. (1994). Relación castellano-aragonesa desde Jaime II a Pedro el Ceremonioso, vol. II. Barcelona, CSIC.

Mata, R. (2014). Paisajes para un desarrollo sustentable y participativo. Urbano, (17-30), 8-21.

Membrado-Tena, J. C. (2013). La división territorial valenciana: antecedentes, problemas y política de la Generalitat. Investigaciones Geográficas, (59), 5-24. https://doi.org/10.14198/INGEO2013.59.01

Membrado-Tena, J. C. (2016). Identificación de orotopónimos irrelevantes mediante lidar. GeoFocus, (18), 25-45. http://dx.doi.org/10.21138/GF.463

Mestre, J. y Sabaté, F. (1998). Atles de la «Reconquesta». La frontera peninsular entre els segles VIII i XV, Edicions 62, Barcelona.

Mitchelson, M., Alderman, D. y Popke, J. (2007). Branded: the economic geographies of MLK streets. Social Science Quarterly, (88), 120-45. https://doi.org/10.1111/j.1540-6237.2007.00450.x

Mitxelena, K. (1997). Apellidos vascos, (5 ed.). San Sebastián: Txertoa.

Montoya, B. (1982). De toponímia local: Una aproximació explicativa. Betània, (30), 104-108.

Moreu-Rey, E. (1982). Els nostres noms de lloc. Palma: Moll.

Muntaner, R. (1325). Crònica I y II. Barcelona: Edicions 62 - La Caixa (ed. 1979).

Nogué, J. (2007). Territorios sin discurso, paisajes sin imaginario: retos y dilemas. Ería, (73-74), 373-382.

Nogué, J. y De San Eugenio, J. (2011). La dimensión comunicativa del paisaje: una propuesta teórica y aplicada. Revista de Geografía Norte Grande, (49), 25-43. http://dx.doi.org/10.4067/S0718$\underline{34022011000200003}$ 
Nogué, J. (2017). El paisatge, entre el subjecte i l'objecte. Discurs de recepció de Joan Nogué i Font com a membre numerari de la Secció de Filosofia i Ciències Socials. Barcelona: Institut d'Estudis Catalans.

Olcina, J., Rico, A. y Paños, V. (2007). Un medio físico de aridez y contrastes con un río-rambla que otorga personalidad geográfica. En Hermosilla, J. (coord.): Los regadíos tradicionales del Vinalopó (Alto y Medio) (pp. 21-30). València: Generalitat Valenciana-Universitat de València.

Pocklington, R. (2010). Toponimia ibérica, latina y árabe de la provincia de Albacete. Al-Basit: Revista de estudios albacetenses, (55), 111-167.

Poirier, J. (1965). Toponymie. Méthode d'enquête. Québec: Les Presses de l'Université Laval.

Ponce, G. y Palazón, S. (1995). El Vinalopó Mitjà. En: Piqueras, J (ed.), Geografía de les comarques valencianes, vol. VI (pp. 105-136).València: Foro.

Poveda, A. M. (1991). Transformación y Romanización del hábitat ibérico contestano de las cuencas alta y media del Vinalopó (Alicante): del final de la República al Alto Imperio. Alebus: Cuadernos de Estudios Históricos del Valle de Elda, (1), 65-78.

Querol, E. (1995). La metodologia en els estudis de toponímia. En: Rosselló, V. M. y Casanova, E. (eds.), Materials de toponímia-I (pp. 61-74). València: Generalitat Valenciana-Universitat de València.

Riesco, P. (2010). Nombres en el paisaje: la toponimia, fuente de conocimiento y aprecio del territorio. Cuadernos Geográficos, (46), 7-34. Recuperado de http://revistaseug.ugr.es/index.php/cuadgeo/article/ view/629/716

Román, J. L. (27 de junio de 2004). Las marismas le dieron su nombre. Información.

Rose-Redwood, R. (2008). From number to name: symbolic capital, places of memory, and the politics of street renaming in New York City. Social and Cultural Geography, (9), 431-52. https://doi. org/10.1080/14649360802032702

Rose-Redwood, R., Alderman, D. y Azaryahu, M. (2010). Geographies of toponymic inscription: new directions in critical place-name studies. Progress in Human Geography, (34- 4), 453-470. https://doi. org/10.1177/0309132509351042

Sánchez, M. J. (1986). Portus Illicitanus: Datos para una síntesis. Santa Pola: ayuntamiento.

Sauer, C. O. (1956). The education of a geographer. Annals of the Association of American Geographers, (46), 287-299. https://doi.org/10.1111/j.1467-8306.1956.tb01510.x

Serrano, M. (2015). La otra isla del tesoro. La isla de Tabarca, fortaleza ilustrada y reserva marina. Revista del Ministerio de Fomento, (655), 50-53.

Tesser, C. (2000). Algunas reflexiones sobre los significados del paisaje para la Geografía. Revista de Geografía Norte Grande, (27), 19-26.

Tort, J. (2000). Toponimia y territorio. Los nombres de los núcleos de población de la comarca del Baix Camp, Tarragona, desde una perspectiva onomasiológica. Scripta Nova, 67. Recuperado de http:// www.ub.edu/geocrit/sn-67.htm

Tort, J. (2001). La toponímia com a camp de coneixement interdisciplinari. Algunes bases teòriques i epistemològiques per a l'estudi dels noms de lloc». Scripta Nova, 86. Recuperado de http://www. ub.edu/geocrit/sn-86.htm

Tort, J. (2010).Toponímia, paisatge i diferenciació del territorio. Societat d'Onomàstica: butlletí interior, (117-118), 463-472.

Villar, F. (1995). Los Indoeuropeos y los orígenes de Europa. Madrid: Gredos.

Villar, F. (2000). Indoeuropeos y no indoeuropeos en la Hispania prerromana. Salamanca: Universidad de Salamanca.

Villar, F, Prósper, B. M., Jordán, C., Fernández, M. P. (2011). Lenguas, genes y culturas en la prehistoria de Europa y Asia suroccidental. Salamanca: Universidad de Salamanca.

Whatmore, S. (2002). Hybrid geographies: natures, cultures, spaces. London: Sage. 